\title{
Capabilities and the Theory of the Firm
}

\author{
Foss, Nicolai J.
}

Document Version

Final published version

Publication date:

1996

License

CC BY-NC-ND

Citation for published version (APA):

Foss, N. J. (1996). Capabilities and the Theory of the Firm. DRUID - Danish Research Unit for Industrial Dynamics. DRUID Working Paper No. 96-08

Link to publication in CBS Research Portal

\section{General rights}

Copyright and moral rights for the publications made accessible in the public portal are retained by the authors and/or other copyright owners and it is a condition of accessing publications that users recognise and abide by the legal requirements associated with these rights.

\section{Take down policy}

If you believe that this document breaches copyright please contact us (research.lib@cbs.dk) providing details, and we will remove access to the work immediately and investigate your claim. 


\section{$\mathbf{D}_{\text {ANISH }} \mathbf{R}_{\text {ESEarch }} \mathbf{U}_{\text {NIT FoR }} \mathbf{I}_{\text {NDUStriat }} \mathbf{D}_{\text {YNamics }}$}

DRUID WORKING PAPER NO. 96-8

\section{Capabilities and the Theory of the Firm}

by

Nicolai J. Foss

June 1996 


\title{
Capabilities and the Theory of the Firm
}

\author{
by \\ Nicolai J. Foss \\ Department of Industrial Economics and Strategy \\ Copenhagen Business School \\ Nansensgade 19,6 \\ 1366 Copenhagen $\mathrm{K}$ \\ Denmark \\ Phone +4538152547 \\ Fax +4538152540 \\ E-mailESNJF@cbs.dk \\ Forthcoming, Revue d'Economie Industrielle
}

\begin{abstract}
The recent decade has witnessed a strong expansion of work on the firm, both from a capabilities perspective and from a contractual perspective. These two bodies of theories are often thought to be fundamentally different, because their domains of applications are different (knowledge-accumulation vs contracts and incentives). However, we need to integrate propositions from capabilities perspectives with ideas about economic organization (markets, hybrids, firms). This is because only a more unified theory will allow us to understand such issues as the dynamics of the modern corporation, and, more topically, the costs and benefits of outsourcing. I discuss the relations between these two bodies of theories. It is possible to argue in favor of a relation of complementarity between the two and pursue a research strategy on this basis. However, it is also possible two claim that they are rivals. Along this line, it is argued that the capabilities perspective contains propositions about economic organization that are not to be found within the modern Coasian approach to economic organization, and thus may be seen as a distinct emerging perspective on economic organization.
\end{abstract}

\section{Keywords}

Economic organization, capability, tacit knowledge

\section{JEL classification}

D23, D40, D83 


\section{Contents}

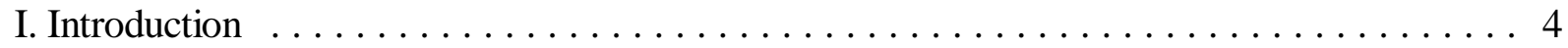

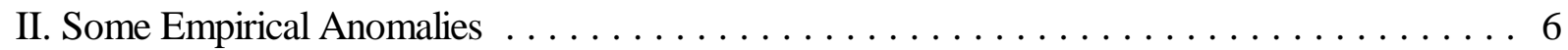

II.i. Alfred Chandler on the Modern Corporation $\ldots \ldots \ldots \ldots \ldots \ldots \ldots \ldots \ldots$

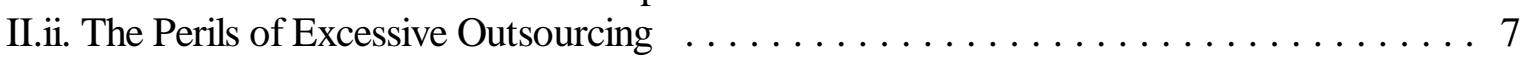

III. Capabilities and Contractual Theories of the Firm $\ldots \ldots \ldots \ldots \ldots \ldots \ldots \ldots$

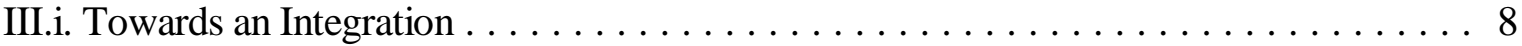

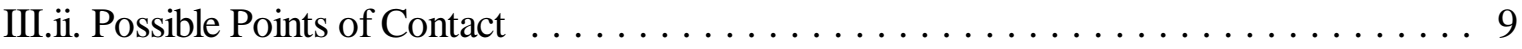

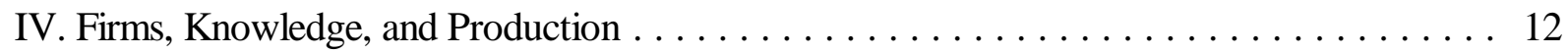

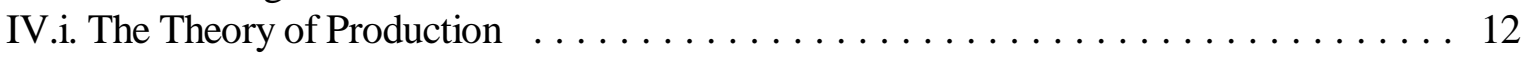

IV.ii. Capabilities perspectives on Productive Activities $\ldots \ldots \ldots \ldots \ldots \ldots \ldots \ldots \ldots$

IV.iii. The Social Character of Knowledge in Firms . . . . . . . . . . . . . . . 14

IV.iv. The Neglect of Production in Contractual Theories . . . . . . . . . . . . . . . . . 15

V. Toward a Capabilities Approach to Economic Organization $\ldots \ldots \ldots \ldots \ldots \ldots \ldots$

V.i. Differential Capabilities and the Boundaries of the Firm $\ldots \ldots \ldots \ldots \ldots \ldots$

V.ii. Production Costs and Communication Costs $\ldots \ldots \ldots \ldots \ldots \ldots \ldots$

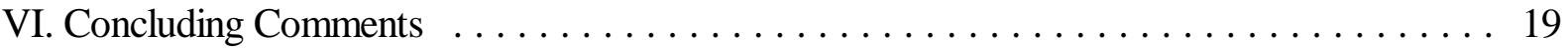

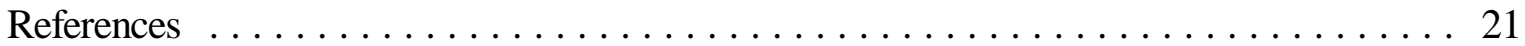




\section{Introduction}

After decades of relative neglect, the theory of the firm has now become one of the most rapidly expanding research areas in economics, winning one of its pioneers, Ronald Coase (1937), the Nobel prize $^{1}$. Much of the frontier research in modern economics is conducted within areas that lie close to or directly within the domain of the theory of the firm, and new mathematical techniques and concepts (e.g., super-modularities, lattice theory) are brought to bear on organizational issues.

The general economic expansion of interest in the firm and in economic organization in general is reflected in a broad menu of contemporary theories of economic organization. Thus, we have Oliver Williamson's (1985) brand of transaction cost economics, nexus of contracts theories (Alchian \& Demsetz, 1972; Cheung, 1983), the more recent outgrowth of these theories, namely agency theory (Holmström, 1982), and the incomplete contract approach pioneered by Grossman and Hart (1986).

Although these contractual theories of the firm differ -- sometimes rather substantially -they are all agreed on emphasizing the importance of property rights, asymmetric information, and some behavioral assumption that extends the usual self-interest assumption (such as 'opportunism' or 'moral hazard'). In lieu of such notions, it is not possible to tell much of a story of why there should be firms in a market economy. In fact, the combined notions of property rights (and therefore incentives), asymmetric information and extended self-interest are necessary for telling this story.

An excellent summing-up of modern contractual economics is provided by Paul Milgrom and John Roberts' recent textbook on Economics, Organization, and Management (1992). However, the title and the content of that book also indicates some problematic features with the new contractual economics: there is many excellent pages on economics and on its application to organizational issues -- but there is actually very little on management proper, not to speak of strategy. The management issue becomes almost completely reduced to providing the right incentives; but surely there is more to management and strategy than this.

In fact, within management studies much has happened with respect to the firm during the last one and half decade. Scholars are increasingly turning away from the pure industry analysis framework associated with Michael Porter (1980). Whereas in the industry analysis framework, the firm is treated as essentially a black box, strategy researchers are now turning towards an approach that places primary emphasis on the firm's endowment of capabilities for understanding the sources of sustained competitive advantages. Capabilities constitute the knowledge base of the firm, and as such belong to the firm level rather than to level of the individual agents. They are normally seen as productive bundles of routines of a highly tacit and social nature, and they are operated by teams of

1 The real pioneer, of course, is Frank Knight, who has the best claim to have founded the theory of economic organization with his Risk, Uncertainty and Profit (1921) (see Foss, 1993; 1996b). 
individuals (primarily the management team, cf. Penrose, 1959) for some strategic purpose (see Metcalfe \& De Liso, 1995).

Firms are seen in this perspective as essentially heterogenous -- and as creating this heterogeneity endogenously (Nelson, 1991). Competitive advantage is accounted for in terms of efficiency differences yielding rents, and sustainability of these advantages are rationalized by pointing to competitors' difficulties of imitation (Wernerfelt, 1984; Barney, 1986a; Winter, 1987; Dierickx \& Cool, 1989) $)^{2}$ I here take the capabilities perspective to also include the evolutionary conceptualization of the firm presented in Nelson and Winter (1982), as well as the dynamic capabilities perspective recently introduced by David Teece and his colleagues (Teece et al., 1995).

The ensuing pages start out from the above relatively recent tendencies in the economic analysis of the firm, that is to say, from capabilities and contractual theories of the firm. I discuss two basic research strategies that has to do with the relations between these theories. The first is the complementarity interpretation, as it is found in recent attempts to bring capabilities and contractual theories together ${ }^{3}$. In this interpretation, there is a tendency to minimize the differences between the capabilities perspective and contractual theories, and instead stress that propositions from both theories may be usefully combined.

I further argue that although it is in fact possible to bring capabilities perspectives and contractual approaches together -- that this is a viable research strategy -- the capabilities perspective implies propositions on economic organization that are not captured by the contractual approach in its present form. Moreover, the perspective does not -- in contrast to contractual theories -- rely on notions of morally hazardous behavior. Consequently, one may see the capabilities perspective as an emerging distinct perspective on economic organization. This is essentially an interpretation that stresses the rivalrous relation between the two sets of theories. It may be defended, for example, by pointing to the very deep underlying differences in terms of which kind of economics the two theories are derived from (evolutionary vs neoclassical economics) or simply by claiming more empirical relevance for the issues investigated in the capabilities perspective relative to the issues investigated in the contractual perspective.

Because these interpretations are likely to influence future work on economic organization, there is a need for clarifying them. This essay represents the beginning of such a clarification. I begin with a basic proposition; one may seem trivial at first: economic organization is extremely sensitive to the assumptions that are made with respect to knowledge. The seeming triviality stems, of course, from the circumstance that it is part of all theories of economic organization that whether knowledge is symmetrically or asymmetrically distributed, whether the future is uncertain or not, etc. make a

2 The most important precursors of this new perspective are probably Penrose (1959), Richardson (1972), Demsetz (1973) and Nelson and Winter (1982). Richardson (1972) coined the 'capabilities' terminology.

3 Foss (1994c) provides an accompanying, but much more methodologically oriented, discussion of 'Why Transaction Cost Economics Needs Evolutionary Economics'. 
crucial difference. For example, it is not possible to discriminate among different kinds of economic organization on grounds of efficiency under full information and no uncertainty; one kind of economic organization is as good (efficient) as any other kind. However, these standard insights are not what really what I am driving at.

Inspired by the capabilities perspective, I shall rather argue that other conceptualizations of knowledge are crucially important and not completely covered by the standard asymmetric information paradigm. Starting from production, rather than from exchange (cf. Richardson, 1972; Loasby, 1994), makes this much clearer. Specifically, the tacit and social components of knowledge as embodied in capabilities matter crucially to economic organization. It is central to the argument that these two dimensions are center stage in capabilities theories of the firm, while they are -- on the whole -- neglected in contractual theories. In short, the overall character of the argument is that for understanding economic organization ${ }^{4}$, we should pay more attention to the issue of the distribution of production knowledge between firms (Demsetz, 1988) -- and in particular to the character of this knowledge.

\section{Some Empirical Anomalies}

In this section, I argue by means of two examples that there is a need for more fully integrating knowledge considerations with considerations of economic organization, such as the issue of the boundaries of the firm. Specifically, existing theory does not allow us to fully understand the modern corporation in its complex entirety, nor does it allow us to understand the more topical theme of outsourcing.

\section{II.i. Alfred Chandler on the Modern Corporation}

Consider Alfred Chandler's (1977, 1990a, 1992) description of the evolution and character of the modern corporation. A key theme here is that the 'visible hand' of the hierarchy differs in essential aspects from the invisible hand of the market in terms of mode of resource allocation (quantities vs prices). In other words, key insights of organizational economics are present in Chandler's work. However, this does emphatically not mean that all of his insights can be reduced to standard organizational economics; in fact, Chandler has grown increasingly skeptical towards Williamson's (1985) brand of organizational economics, which he once embraced. As Chandler's reflections on the matter confirm, this is essentially because the corporation is not only a contractual entity -- it is just as much a part of its 'essence' that it is a learning and innovating entity that seeks competitive advantage from

4 However, I shall only be concerned with the issue of the boundaries of the firm and neglect internal organization and existence issues. 
scale and scope advantages based on superior capabilities. In fact, as Chandler (1992) now tells the story, the firm exists because it is a hotbed for the cultivation of innovative capabilities. Such capabilities do not square easily with market relations.

This would seem to imply a ringing endorsement of the merits of vertical integration. And, indeed, according to Chandler (1990b), being big and heavily vertically integrated is one condition for successful performance, at least on the global arena; this best makes it possible to stimulate efficient throughput, innovation and development of capabilities ${ }^{5}$. Arguably, vertical integration is currently out of fashion, and at any rate, Chandler's views are flatly contradicted by those who advocate 'the virtual corporation', to wit, the relatively short-lived but extremely flexible partnering that develops in order to reap temporary technological opportunities, as the organizational form of the future, by the advocates of 'networking', 'industrial districts', etc.

On whose side should we place out bets? The problem is that our existing theoretical apparatus does not really allow us to say much meaningful about when and under which circumstances Chandler-type firm organization dominates 'the virtual corporation' (and similar de-centralized types of organization) and vice versa ${ }^{6}$. We could, of course, examine and compare the transaction properties of each kind of organization at a given point of time. However, this would lead us to neglect the more dynamic aspects: an organization that is burdened by heavy transaction costs -- for example, because of a strong internal variety of behaviors which result in agency problems -- may nevertheless display superior survival capability, because its variety of behaviors allow it to engage in learning that lead to dynamic efficiency. Alternatively, we could focus on only dynamic efficiencies and forget about static efficiencies. Or, one could deem neither alternative attractive, and call for some integrated framework that has room for both sides of the story, that is to say, features both propositions about knowledge-accumulation and propositions about more static transaction cost issues.

\section{II.ii. The Perils of Excessive Outsourcing}

Another -- but closely related -- example has to do with the current debate on outsourcing (as summarized in Bettis, Bradley and Hamel, 1992). Outsourcing simply means letting suppliers take over activities that were once undertaken in-house; thus, it is an instance of vertical disintegration. Because it allows the firm to get access to the high-powered incentives of market supply (rather than

5 And see Lazonick (1991) for an even more radical view that proceeds in terms of a complete dichotomization between market and hierarchy. Lazonick in particular, but also to some extent Chandler, may be criticized for having a much too stylized view of "the market", one that neglects both the empirical reality of all sorts of long-lived cooperative relations between firms and the theoretical message of such seminal contributions as Richardson (1972). change on economic organization, designed for addressing and answering such questions. 
internal procurement) and because it allows the firm to eliminate some fixed costs, outsourcing may be an attractive strategy, particularly for lagging business units.

However, unless it is carefully executed, this strategy will from a Chandlerian perspective be associated with serious perils. In fact, the critics of outsourcing have (unknowingly) taken a Chandlerian position and have argued that excessive outsourcing on the part of Western firms to Japanese and South-East Asian firms has led to a loss of ability to upgrade capabilities on the part of Western firms in many industries. Thus, the pursuit of static efficiency has harmed dynamic efficiency. This is so, because Western firms have not understood the strategic intentions of their Asian suppliers (namely to learn from the relation rather than to simply supply) who have later emerged as vigorous competitors, have allowed Asian supplier firms to get 'too close' to core capabilities, have lost track of important technological developments in components and the manufacture of components, etc.

How should we theoretically approach this story? Notice that the outsourcing story essentially says that the problems are caused by 1) overly myopic strategic beliefs (which lead to a focus on short-term cost-cutting by means of outsourcing), leading to 2) changes in the boundaries of the firm (vertical disintegration), 3) retarding the learning capacity of the firm, and therefore 4) destroying the firm's ability to upgrade its capabilities, harming its long run competitive advantage. In other words, understanding the dynamics of outsourcing requires an understanding of the interplay between the development of the knowledge assets of the firm and it boundaries.

Thus, the two above examples are only instances of the broader problem of understanding how knowledge and the boundaries of the firm interact. This problem was first clearly articulated by such post-Marshallian economists as Harold Malmgren (1961) and George Richardson (1972) (Foss, 1995), but was for long left unexamined by the modern heirs to Coase's contractual analysis. However, they have now increasingly realized that there may be a need to combine propositions from capabilities and contractual theories. In the following section, I discuss some work along these lines.

\section{Capabilities and Contractual Theories of the Firm}

\section{III.i. Towards an Integration}

As presented in the works of Williamson, Alchian and Demsetz, Grossman and Hart and others, the contractual approach is probably best understood as an extension of the traditional microeconomic theory of allocation and optimality ${ }^{7}$. One consequence of this is that its primary object of explanation is the efficient organization of existing economic resources. It is outside the prerogative of standard contractual analysis to examine how new resource uses are discovered, how resources are accumula-

Again, Milgrom and Roberts' (1992) textbook provides evidence here: the book essentially relies on the Arrow-Debreu framework in developing insights in economic organization. 
ted, how firms learn, which governance structures best promote learning under which circumstances, etc. The economic problem has to do with combining inputs and outputs in a transaction cost minimizing way, given technology, inputs and outputs. Issues such as the dynamics of outsourcing or the evolution of the modern corporation cannot be approached in their complex entirety.

It is probably as a result of a recognition of such current limitations that David Teece identifies the following desideratum:

'[i]n order to fully develop its capabilities, transaction cost economics must be joined with a theory of knowledge and production' (Teece, 1990: 59).

Clearly, Professor Teece is the right person to issue such a verdict: his own work demonstrates that issues such as diversification (Teece, 1982) and the innovation boundaries of the firm (Teece, 1987b) are best approached in terms of a theory that combines capability and contractual theories. It will do for understanding such phenomena to conceptualize the firm as simply a nexus of contracts among input owners.

Teece's position has recently been echoed by Oliver Williamson. The earlier versions of what may be called Williamson's 'efficiency hypothesis' asserted that transactions are aligned with those types of economic organization that minimize the costs of organizing those transactions. However, now the efficiency-hypothesis goes the following way:

\begin{abstract}
'Align transactions, which differ in their attributes, with governance structures, which differ in their costs and competences in a discriminating (mainly, transaction cost economizing) way' (Williamson, 1991a: 79; my emphasis).
\end{abstract}

In other words, Teece, and now also Williamson, recognize the need for supplementing the notion of the firm as a contractual entity with a notion of the firm as a bundle of capabilities. What is, however, open to discussion is the actual mechanisms that their conceptualizations conceal or sidestep. How should it be done? How precisely do capabilities influence transaction costs, and therefore the boundaries of the firm? In the following sections, I identify some possible mechanisms.

\title{
III.ii. Possible Points of Contact
}

As already indicated, a small, but growing, literature has addressed the relation between firms' capabilities and their boundaries ${ }^{8}$. The majority of these studies implicitly or explicitly accept the proposition that efficient economic organization is above all a matter of somehow aligning the

8 Some representatives are Teece (1982, 1987b, 1990), Klein (1988), Kreps (1990), Reve (1990), and Dosi, Winter and Teece (1992). 
incentives that cooperating input-owners face. Nevertheless, it is still possible in principle to add capabilities considerations to basic incentive ideas and vice versa. For example, one may argue that the full realization of the rent-yielding potential of capabilities requires incentives that harmonize the actions of resource-owners, and provide stimuli to investment in the accumulation of human capital. Thus, contractual theories may help us better understand the organization and accumulation of capabilities (cf. Milgrom \& Roberts, 1992). This is a clear complementarity between the two theories. But the complementarity is potentially double-sided -- for the notion of the firm as a bundle of capabilities may influence propositions from contractual theories of economic organization, too. Consider the following points.

A) Connecting to agency problems of internal organization. The notion of capabilities connects to contractual theories of the agency variety ${ }^{9}$. This is because the presence of capabilities in firms may influence the outcomes of principal-agent-type problems. Firms will often be characterized by a distinct 'way of doing things' that is shared among input-owners. Such shared (common) knowledge may significantly reduce moral hazard and adverse selection problems, simply by making asymmetric information problems less severe, and therefore reduce overall agency costs. This is a possible interpretation of why corporate cultures may be valuable assets to firms.

B) Connecting to incomplete contract logic. According to incomplete contract theorists, a certain pattern of asset ownership is the hallmark of the firm. Specifically, owners/managers possess residual decision rights to the firm's physical assets (Grossman \& Hart, 1986) ${ }^{10}$. However, the theory does not say anything directly about how owners/managers exercise those rights. For example, they may opportunistically hold-up employees, appropriating part of their share of the overall rents. In other words, a latent prisoners dilemma-game exists between the two parties. Utilizing the theory of the iterated prisoners' dilemma-game, Kreps (1990) argues that repeating such games may produce supergames -- norm equilibria -- that may be interpreted as organizational cultures, that is, as an organizational dimension of capabilities. Because many outcomes are theoretically possible, the observed heterogeneity of firm cultures is partly accounted for. Since cultures may have strong productivity implications and may be largely inimitable, they may possess rent-earning potential (Barney, 1986b).

C) Broadening the concept of Williamsonian asset specificity. A broader notion of Williamson's concept of asset-specificity is suggested by capabilities theories (Klein, 1988; Winter, 1988; Reve, 1990). Williamson (1985: 55) mentions four types of asset specificity, namely human capital

9 However, as far as I know, no formal models have been developed of the connection.

10

Rabin (1993) and Brynjolfsson (1994) extend the basic Grossman and Hart analysis to knowledge assets. 
specificity, site specificity, physical specificity, and specificity in terms of dedicated assets. These do not incorporate capabilities; however, capabilities may be added to the list, and carry the same implications for economic organization. As Torger Reve (1990: 137) formulates it: 'Core skills are of high asset specificity and can only be governed internally ${ }^{\prime 1}$. Since capabilities may not only yield high Ricardian (efficiency) rents, but also high Paretian (quasi-)rents, standard reasoning dictates that they be governed internally.

D) Allowing more realistic analysis of the scope of the firm. Casual empiricism confirms that almost no firm has integrated the entire value-chain, the common explanation being that the firm confronts increasing diseconomies of scope as it integrates activities that demand capabilities that are increasingly dissimilar relative to the firm's own capabilities (Richardson, 1972). A similar explanation applies to the explanation of diversification. This is a production oriented explanation, that may, however, be given an interpretation in terms of incentives: as the firm moves increasingly away from its core business, it confronts increasing adverse selection and moral hazard problems, since management becomes increasingly unable to efficiently monitor employees or evaluate their human capital. Agency costs rise correspondingly, producing the net profitability disadvantage associated with further integration.

E) Connecting to appropriability and innovation issues. Teece (1982, 1987b, 1990), among others, has argued that there is a direct connection between the degree of appropriability a firm confronts and its efficient (innovation) boundaries. For example, to the extent that the firm produces valuable knowledge that is ill-protected by intellectual property rights, this may underlie expansions of vertical as well as horizontal scope. However, if the firm on the other hand develop knowledge that is hard to imitate, it may choose its boundaries much more narrowly. Generally, the more complex and/or tacit the firm's knowledge base is, the fewer activities it has to integrate in order to 'isolate' (Rumelt, 1984) rents.

As can be inferred from an inspection of points A) to E), adding a notion of the firm as a bundle of capabilities to the standard contractual theories does not change their fundamental logic; it constrains the set of possible outcomes, but does not change the basic explanatory mechanisms. Thus, on this reading, economic organization is first and foremost a matter of property rights and incentives. With respect to economic organization, capabilities and cognition are secondary; incentive considerations are primary, 'exchange' dominates 'production'. The following sections try to resurrect the balance somewhat. By doing so, I now leave what was called the 'complementarity interpretation':

11 Winter (1988: 178-179) further adds: "Evolutionary economics suggests that the concept of human asset specificity is central to understanding the functioning of the firm as a repository of knowledge. For understanding to progress, however, the idea of "specificity" must be refined and linked to the broader context in which quasi-rents to various sorts of productive knowledge are determined". 
instead of stressing complementarities between the two theories, I now lean more towards the interpretation that stresses their different and perhaps even rivalrous nature.

\section{Firms, Knowledge, and Production}

I plan to argue that capabilities theories implicitly have things to say about economic organization that are different from the standard contractual approaches ${ }^{12}$. Preliminaries to this argument is the arguments that 1) how knowledge is conceptualized is extremely important to the theory of economic organization; 2) the incentive-based contractual approaches incorporate an impoverished conception of knowledge; and 3) there are determinants of economic organization that differ from those usually considered in the standard approach. Specifically, superadditive interdependencies (i.e., economic complementarities) among activities are highlighted by capabilities theories, but neglected in contractual theories. However, these interdependencies strongly influence economic organization. To see this, let us begin where earlier writers (e.g., Richardson, 1972) advice us to begin our understanding of economic organization, namely with the theory of production.

\section{IV.i. The Theory of Production}

The standard microeconomic theory of production and its uses have often been up for attack. Assuredly, the standard theory is not fallacious per se or misplaced for all purposes. The argument of the critics is rather that for some purposes, it is likely to seriously mislead. Such purposes include the theory of economic organization. For example, Williamson (1985) points out that the standard theory of production has been misused to arrive at a 'production function approach' to the firm, according to which the firm is simply an efficient input-combiner. Evolutionary economists, such as Nelson and Winter (1982) have phrased their critique somewhat differently: what they criticize is the atemporal character of the standard theory. This implies a neglect of the sequentiality of productive operations and the role of tacit accumulated knowledge in production.

We may add that the framework is couched in equilibrium terms which taken together with the neglect of tacit knowledge implicitly means that all profitable technological knowledge is shared among firms. This means that in the standard setting, what one firm can do, another firm can in principle do equally well (Demsetz, 1988) -- a complete denial a fundamental idea of economics: the division of labor. This absurdity comes about because knowledge transfer is assumed costless and superior knowledge will not remain unexploited by competitors. Finally, the assumption of instantaneous factor-combination obscures the fact that production takes place through a process of explicit and

12 When I talk about 'standard contractual approaches' here and in the following, I except those contributions, such as Teece $(1982,1987 b)$, that are well aware of the need to integrate production and contractual considerations. 
implicit contract drafting, execution, monitoring, socialization, etc. among agents, that knowledge has to communicated, actions coordinated, etc.

All these unfortunate characteristics of the standard theory of production may have led to the abandonment of a theory of production within contractual theories of the firm. However, nothing has been constructed to replace the standard theory. Thus, paradoxically the conceptualization of production in the standard theory seems somehow to have been carried over to the contractual approach (Demsetz, 1988): one often gets the impression that what has been added to the standard microeconomic theory of production is merely an analysis of which incentives will bring the firm closest to its production possibility frontier. Specifically, I argue that the continued, but implicit, dominance of the framework has led scholars within the theory of economic organization to

- largely neglect the role of tacit knowledge, implying that it becomes more legitimate to assume that all knowledge for production purposes is shared among firms;

- neglect the social aspect of much productive knowledge (with the same implication as above);

- assume that production costs do not vary over firms for the 'same' productive tasks -- that is, what one firm can do, another firm can do equally efficient;

- and, as a consequence of all this, not allow the boundaries issue to turn on differences in firms' endowments of productive knowledge, that is, their capabilities.

I the following, I briefly expand on these assertions, and also try to look at which implications for economic organization may follow from a perspective that explicitly breaks with the standard theory of production. As I see it, the capabilities perspective effectively performs this break.

\section{IV.ii. Capabilities perspectives on Productive Activities}

In spite of a honorable prehistory that goes back at least to Alfred Marshall (Loasby, 1994), the capabilities perspective is perhaps most often with Nelson and Winter (1982). As they are at pains to emphasize, productive activities are not best understood as a matter of applying commonly accessible explicit knowledge ('blueprints') in the instantaneous and profit-maximizing combination of factors of production. Rather, such activities involve processes of accumulation of partly tacit knowledge through various largely incremental learning-processes (learning by doing, by using, and by searching). This tends to make the firm's course of development path-dependent. It is ultimately these properties that make firms differ. As Penrose (1959: 74) notes, it is the heterogeneity of the flows and stocks of knowledge within firms -- not their physical resources -- that gives each firm its unique character. Essentially, this is because physical resources can normally be acquired and combined by, in 
principle, anybody, whereas knowledge assets, such as routines and capabilities, are difficult to transfer, sell, communicate, etc.

\section{IV.iii. The Social Character of Knowledge in Firms}

In addition to its being tacit, much productive knowledge is an emergent aspect of the interaction of many agents. As such it often has an existence that is, in a sense, independent of individual agents. Thus, BMW's capabilities in high-precision engineering will not be substantially influenced by one engineer's exit from that organization. In other words, the relevant knowledge capital assets are firmspecific rather than agent-specific. Thus, firms come equipped with more knowledge than is embodied in the sum of individual agents' human capital, as it were. This is precisely what Nelson and Winter (1982: 124) mean by 'routine'; as they define it, 'Routines are the skills of an organization'. Levitt and March (1988: 320) further expand the concept by seeing it as

'...the forms, rules, procedures, conventions, strategies, and technologies around which organizations are constructed and through which they operate. It also includes the structure of beliefs, frameworks, paradigms, codes, cultures, and knowledge that buttress, elaborate and contradict the formal routines'.

It is the emphasis on the social nature and the large degree of tacitness of routines that underlies a crucial point in the capabilities perspective: that it is difficult -- both empirically and conceptually -- to fully separate technology, production and organization. As Nelson and Winter (1982: 104) argue '...skills, organization and 'technology' are intimately intertwined in one functioning routine and it is difficult to say exactly where one aspect ends and another begins'. Prahalad and Hamel (1990) also see technology and organization as strongly intertwined and not fully separable. Consider, for example, their (1990: 82) definition of 'core competence' as '...the collective learning in the organization, especially how to coordinate diverse production skills and integrate multiple streams of technologies'.

As these definitions suggest, routines, core competencies, capabilities, or whatever we decide to call these knowledge assets are characterized by strong interdependencies (complementarities) among activities and the agents participating in activities. As Richardson (1972) phrased it, 'closely complementary activities' are involved. These interdependencies may yield superior efficiencies (because of various sub-additivities); as a result, the capabilities that embody them may be valuable, rent-earning assets to firm (Winter, 1987; Reed \& DeFilippi, 1988). Moreover, as I later argue, these interdependencies are important for understanding economic organization in the context of a capabilities perspective. 


\section{IV.iv. The Neglect of Production in Contractual Theories}

Harold Demsetz (1988: 148) recently argued that in the contractual approach

'...in some respects, information remain full and free. Although information is treated as being costly for management control purposes, it is implicitly assumed to be free for production purposes. What one firm can produce, another can produce equally well, so that the make-or-buy decision is not allowed to turn on differences in production cost'.

However, Demsetz did not identify the underlying reasons why knowledge for production purposes is normally treated in this way in contractual theories. Based on the above discussion, I submit that the reason is that knowledge for production purposes is not here represented as fundamentally tacit and social. But if such knowledge is individualized and codifiable, it is surely a reasonable approximation to assume that it will 'remain full and free'. This is so, because codifiable knowledge is easily spread, and particularly so when it is not something that is inherent in the interaction between agents, but can transferred across the boundaries of the firm by a single agent.

To the extent that firms differ in contractual theories (at least in their more neoclassical versions), this is a matter of different endowments and/or asymmetric information. Specifically, a firm may come equipped with a better transaction technology than another firm. However, capabilities are conceptually distinct from endowments or information partitions: unlike endowments they change through learning and application to problem-solving, and because of their tacit component, capabilities do not necessarily increase as information becomes more perfect (Dosi \& Marengo, 1993).

I shall argue that beginning with a theory of production that emphasizes the tacit and social aspects of productive activities may lead to insights in economic organization that differ from standard contractual theories. It is fundamentally a similar recognition that explains why Alfred Chandler has now grown much more skeptical towards contractual theories of economic organization than he was previously. As he says, if

'...the firm is the unit of analysis, instead of the transaction, then the specific nature of the firm's facilities and skills becomes the most significant factor in determining what will be done in the firm and what by the market' (Chandler, 1992: 86; my emphasis).

Thus, according to Chandler, the standard contractual approach may not have captured all determinants of the boundaries of the firm. This has also been argued by none other than Ronald Coase (1990): 
'...while transaction cost considerations undoubtedly explain why firms come into existence, once most production is carried out within firms and most transactions are firm-firm transactions and not factor-factor transactions, the level of transaction costs will be greatly reduced and the dominant factor determining the institutional structure of production will in general no longer be transaction costs but the relative costs of different firms in organizing particular activities' (p.90).

We may interpret Chandler and Coase to be in agreement in seeing firms' endowments of capabilities as something that co-determine their boundaries. They are also agreed that this is not fully captured within the standard contractual framework. I expand on their assertions in the following.

\section{Toward a Capabilities Approach to Economic Organization}

\section{V.i. Differential Capabilities and the Boundaries of the Firm}

One obvious implication of the capabilities perspective on productive activities is that production costs are something extremely specific to individual firms (Langlois, 1992). This is because the underlying capabilities are correspondingly specific. Two different firms simply will not have the same costs of carrying out the 'same' productive operation (Richardson, 1972). This is what specialization and the division of labor is all about. And at the root of the benefits of specialization is accumulation of more-or-less tacit knowledge, not only in the form of individual skills (as in Adam Smith's pin factory), but more importantly in the form of the firm-specific knowledge capital represented by capabilities. The emphasis on heterogeneous firm capabilities has been used in the literature to account for inter- and intra-industry dispersals of return (Lippman \& Rumelt, 1982), and for theorizing the foundations of competitive advantage (Teece et al., 1995). But it also has implications for the theory of economic organization.

The crucial concept of the capabilities perspective may well be that of heterogeneity. For example, it is basically heterogeneity that gives rise to differential rents and therefore differential competitive success. Many attempts to pin down the conditions that must obtain for capabilities to yield long-lived rent have been put forward ${ }^{13}$. However, they are all in agreement that one important condition is (strict or limited) in-imitability of the capability in question, that is to say, imitation costs are very large or even infinite.

Searching for the characteristics that make assets non-imitable, Reed and DeFilippi (1990) identify tacitness, complexity, and specificity as the crucial characteristics underlying imitation costs. Clearly, these are characteristics of capabilities -- in fact, capabilities are particularly likely to satisfy

13 Peteraf (1993) provides an excellent review of the literature. 
these conditions. For example, capabilities are not bound to individual input-owners but are tied to the interaction of a number of input-owners and acquire some permanence over time. Moreover, while tangible assets may be the sources of initial competitive advantages, it seems intuitively likely that only non-tangible assets can be sources of long-lived (sustainable) advantage, since most tangible assets can be bought on factor markets, reverse-engineered, etc.

Tacitness, complexity and specificity are also the reasons why capabilities will typically be difficult to trade. A reason for this is that because of their very idiosyncracy, the market cannot easily evaluate their worth on the basis of an observable and verifiable marginal product (Foss, 1993). Rather than being traded, capabilities are accumulated internally (Dierickx and Cool, 1989). It is also the difficulties of trading capabilities that explains why capabilities may determine the boundaries of the firm. Thus, there is a nice parallel here between the conditions for competitive advantage and the reasons why capabilities determine the boundaries of the firm. Specifically, the social, tacit, and complex aspects are also important for understanding the boundaries of the firm. For example, tacitness make capabilities hard to imitate, and therefore a potential source of competitive advantage; but tacitness also gives rise to information costs, hence influences the boundaries of the firm ${ }^{14}$.

That capabilities influence the boundaries of the firm was clearly glimpsed by the perhaps most important precursor of the capabilities perspective, Edith Penrose, when she observed that

'...integration may appear profitable because the firm believes it can produce some of its requirements...much more cheaply than it can obtain them in the market' (1959: 148).

Thus, according to Penrose, an activity may be internalized because the cost of production may be lower than the prices emerging from market exchange -- quite apart from any incentive considerations. The firm internalizes an activity because it can carry out production in a more production cost efficient manner. This cannot take place within the settings described by contractual theories, since the make or buy decision is not allowed to turn on considerations of capabilities.

However, differential capabilities, and therefore production costs, are empirically significant variables for explaining the boundaries of the firm. In Walker and Weber's (1984) empirical study of the make and buy decision, the most explanatorily important variable was the indicator for differential firm capabilities, that is, production costs. And in the Monteverde and Teece (1982) study that aimed to support the standard contractual approach, the most significant variable was the dummy for the firm, representing the heterogenous and unobserved firm effects (Kogut and Zander, 1992: 394). To

14 Something similar is suggested by Nelson and Winter (1982: 119): "The point emphasized by evolutionary theory is that a firm with an established routine possesses resources on which it can draw very helpfully in the difficult task of attempting to apply that routine on a larger scale..The replication assumption in evolutionary models is intended to reflect the advantages that favor the going concern attempting to do more of the same, as contrasted with the difficulties that it would encounter in doing something else or that others would encounter in trying to copy its success" (my emphasis). 
these quantitative statistical studies, we may add Chandler's (1990a, 1992) detailed qualitative studies which basically amount to the same thing: that it is '...the specific nature of the firm's facilities and skills' that most significantly determines '...what will be done in the firm and what by the market' (Chandler, 1992: 86), rather than the incentive costs of internal governance relative to the incentive costs of market governance.

\section{V.ii. Production Costs and Communication Costs}

Although the above explanation because of its basis in a capabilities view of the firm tends to direct our attention to production cost for explaining the boundaries of the firm, on a somewhat different level communication cost considerations enter the story. Metaphorically, one may say that the firm knows more than its contracts can tell (Kogut \& Zander, 1992): because of the specificity and tacitness of capabilities, not all of that the firm knows can be communicated to other firms. For example, firms may confront difficulties communicating with suppliers who do not understand (at a desirable level of communication costs) specifications of components; as a result, the firm may decide to undertake production itself.

This communication cost interpretation is, however, simply one side of the coin, the capabilities/production cost interpretation being the reverse. They are both made of the same stuff, namely the emphasis on the firm as a repository of capabilities that cannot easily or efficiently be transferred over the boundaries of the firm. Note that this story has nothing to do with incentive considerations. Rather, it appeals to a species of transaction costs that fundamentally touches on issues of information and communication rather than on divergent interests (Langlois, 1992).

What drives the story is basically the assumption that agents through working together, learning the norms and cultures of firms, etc. become equipped with models of the world that differ from those hold by other agents. This is something different from and deeper than the standard asymmetric information assumption. The form of representation of the capability theory of the boundaries of the firm is coordination games rather than prisoners' dilemma-games (Foss, 1993) ${ }^{15}$; it is a matter of getting agents to understand each other in the first place, rather than avoiding strategic behavior by agents who have already a detailed understanding of each other.

15 This is contrary to the thrust of, for example, the incomplete contract-approach of Grossman and Hart (1986). Here it is maintained that communication channels are chosen endogenously, so that information cost considerations cannot determine governance structures. Only incentive considerations do so. The Grossman and Hart-argument seems, however, to presuppose a high degree of flexibility of communication channels, when it may in reality take very long to build them up. Underlying this may be the fact that Grossman and Hart (like Williamson) fundamentally abstract from the "social capital" embodied in capabilities. Only (inalienable) human capital is considered. 


\section{Concluding Comments}

In this essay, I have discussed the relations among contractual and capabilities theories of the firm. A distinction was introduced between a complementarity interpretation, according to which there was no fundamental conflict between the two bodies of theories, and a interpretation that stressed rivalry and according to which the capabilities perspective was a distinct emerging perspective on economic organization that differed in important ways from contractual perspectives.

Attempts to integrate key ideas from the two bodies of theories, following the complementarity interpretation, were reviewed. In most of these attempts, the incorporation of capabilities in an otherwise unchanged contractual set-up merely functions to constrain the set of possible outcomes from settings with misaligned incentives.

The other interpretation, stressing rivalry, led to a brief sketch of a distinct theory of the boundaries of the firm derived from capability-based insights in productive activities. This alternative interpretation allows the boundaries of the firm to turn on considerations of production costs, or, equivalently, communication costs that are conceptually unrelated to problems of aligning incentives. The overall conclusions that were arrived at are:

- The important rent-yielding assets among firms' total asset-endowments are those that are social and tacit. These characteristics make them impossible or difficult to trade and imitate -- and more so than other assets. Capabilities represent such assets.

- One firm may be able to carry out a productive task more efficiently than another firm, not necessarily as a result of superior incentives, but because of superior learning, cognition, etc. -- in sum, the advantages normally associated with specialization. This difference in terms of efficiency may help to explain the boundaries of the firm, in the sense that a firm may internalize an activity because it can carry it out in a more cost-efficient way.

- The other side of differential capabilities explaining the boundaries of the firm is communication costs. Because of the above-mentioned characteristics of a capability, it may be costly to communicate to, for example, suppliers. In a sense, firms know more than their contracts can tell. Thus, the tacit and social aspects of capabilities explain why they may yield a competitive advantage and they are the factors that explain why capabilities influence the boundaries of the firm.

Thus, it is possible to construct propositions about economic organization that do not directly turn on considerations of morally hazardous behavior and incentive alignment. Instead, economic organization is fundamentally a matter of economizing with knowledge costs (Demsetz, 1988). 
I have tried to refrain from too explicitly taken a side on which interpretation is 'the right one', although the reader may have sensed that my sympathies lies with the attempt to construct a distinct capabilities theory of economic organization. However, it is certainly possible to argue sensibly in favor of both interpretations. Therefore, my primary aim has been to clarify positions and interpretations, so that a somewhat clearer roadmap for future research in economic organization may emerge. 


\section{References}

Alchian, Armen A. and Harold Demsetz (1972): Production, Information Costs and Economic Organization. In Armen A. Alchian (1977): Economic Forces at Work. Indianapolis: Liberty Press.

Arrow, Kenneth J. (1974): The Limits of Organization. New York: Norton.

Barney, Jay B. (1986a): Strategic Factor Markets. Management Science 32: 1231-1241.

Barney, Jay B. (1986b): Organizational Culture: Can It Be a Source of Sustained Competitive Advantage? Academy of Management Review 11: 656-665.

Barney, Jay B. and William G. Ouchi (eds.) (1988): Organizational Economics. San Francisco: Jossey-Bass Publishers.

Bettis, Richard A., Stephen P. Bradley and Gary Hamel (1992): Outsourcing and Industrial Decline. Academy of Management Executive 6: 7-22.

Brynjolfsson, Erik (1994): Information Assets, Technology, and Organization. Management Science 40: 1645-1662.

Chandler, Alfred D. (1977): The Visible Hand. Cambridge: Harvard University Press.

Chandler, Alfred D. (1990a): Scale and Scope: The Dynamics of Industrial Enterprise. Cambridge: Harvard University PreSs.

Chandler, Alfred D. (1990b): The Enduring Logic of Industrial Success. Harvard Business Review 66: 130-140.

Chandler, Alfred D. (1992): Organizational Capabilities, and the Economic History of the Industrial Enterprise. Journal of Economic Perspectives 6: 79-100.

Cheung, Stephen N.S. (1983): The Contractual Nature of the Firm. Journal of Law and Economics 26: 1-22.

Coase, Ronald H. (1937): The Nature of the Firm. Economica 4: 386-405.

Coase, Ronald H. (1990): Accounting and the Theory of the Firm. Journal of Accounting and Economics 12: 3-13.

Demsetz, Harold (1973) : Industry Structure, Market Rivalry, and Public Policy. Journal of Law and Economics 16: 1-10.

Demsetz, Harold (1988): The Theory of the Firm Revisited. Journal of Law, Economics and Organization 4: 141-162.

Dierickx, Ingemar and Karel Cool (1989): Asset Stock Accumulation and Sustainability of Competitive Advantage. Management Science 35: 1504-1511.

Dosi, Giovanni, Roberto Giannetti and Pier-Angelo Toninelli (eds.) (1992): Technology and Enterprise in a Historical Perspective. Oxford: Clarendon Press.

Dosi, Giovanni, Sidney G. Winter and David J. Teece (1992): Towards a Theory of Corporate Coherence. In Dosi, G., $R$. Giannetti, and P.A. Toninelli (1992).

Dosi, Giovanni and Luigi Marengo (1993): Some Elements of An Evolutionary Theory of Organizational Competencies. CCC Working Paper No.93-14, University of California, Berkeley.

Foss, Nicolai J. (1993): Theories of the Firm: Contractual and Competence Perspective. Journal of Evolutionary Economics 3: $127-144$.

Foss, Nicolai J. (1994a): The Two Coasian Traditions. Review of Political Economy 6: 37-61. 
Foss, Nicolai J. (1994b) : Why Transaction Cost Economics Needs Evolutionary Economics. Revue d'Economie Industrielle 68: 7-26.

Foss, Nicolai J. (1995) : Austrian and Post-Marshallian Economics: Change and Organization in the Context of George Richardson's Work. In N.J. Foss and B.J. Loasby (eds.): Capabilities and Coordination: Papers in Honour of George Richardson, forthcoming.

Foss, Nicolai J. (1996a): Knowledge-Based Approaches to the Theory of the Firm: Some Critical Comments. Forthcoming in Organization Science.

Foss, Nicolai J. (1996b): The 'Alternative' Theories of Knight and Coase, and the Modern Theory of the Firm. Forthcoming in Journal of the History of Economic Thought.

Foss, Nicolai J. (1996c): Firms, Incomplete Contracts, and Organizational Learning. Forthcoming in Human Systems Management.

Grossman, Sanford and Oliver Hart (1986): The Costs and Benefits of Ownership: A Theory of Vertical and Lateral Integration. Journal of Political Economy 94: 691-719.

Holmström, Bengt (1982): Moral Hazard in Teams. Bell Journal of Economics 13: 324-340.

Holmstrom, Bengt and Jean Tirole (1989): The Theory of the Firm. In Richard Schmalensee and Robert D.Willig (eds.) (1989): Handbook of Industrial Organization, Vol.1. Amsterdam: North-Holland.

Klein, Benjamin (1988): Vertical Integration as Organizational Ownership. Journal of Law, Economics and Organization 4: 201-213

Kogut, Bruce and Udo Zander (1992): Knowledge of the Firm, Combinative Capabilities, and the Replication of Technology. Organization Science 3: 383-397.

Kreps, David M. (1990): Corporate Culture and Economic Theory. In Alt,J. and K. Shepsle (eds.) (1990): Perspectives on Positive Political Economy. Cambridge: Cambridge University Press.

Langlois, Richard N. (1992): Transaction-Cost Economics in Real Time. Industrial and Corporate Change 1: 99-127.

Langlois, Richard N. and Paul H. Robertson (1995): Firms, Markets, and Economic Change. London: Routledge.

Lazonick, William (1991): Business Organization and the Myth of the Market Economy. Cambridge: Cambridge University Press.

Leonard-Barton, Dorothy (1992): Core Capabilities and Core Rigidities: A Paradox in Managing New Product Development. Strategic Management Journal 13: 111-125.

Levitt, Barbara and James G. March (1988): Organizational Learning. American Review of Sociology 14: 319-340.

Lippman, Stephen A. and Richard P. Rumelt (1982): Uncertain Imitability: An Analysis of Interfirm Differences in Efficiency under Competition. Bell Journal of Economics 13: 418-438.

Loasby, Brian J. (1994): Organizational Capabilities and Interfirm Relations. Metroeconomica 45: 248-265.

Malmgren, Harald B. (1961): Information, Expectations, and the Theory of the Firm. Quarterly Journal of Economics 75 : $399-421$.

Metcalfe, John Stanley and N. De Liso (1995): Innovation, Capabilities and Knowledge: The Epistemic Connection. Unpublished ms. 
Milgrom, Paul and John Roberts (1992): Economics, Organization, and Management. Englewood Cliffs: Prentice Hall.

Monteverde, Kirk and David J. Teece (1982): Supplier Switching Costs and Vertical Integration in the Automobile Industry. Bell Journal of Economics 13: 206-213.

Nelson, Richard R. (1991): Why Do Firms Differ, and How Does It Matter? Strategic Management Journal 14: 61-74.

Nelson, Richard R. and Sidney G. Winter (1982): An Evolutionary Theory of Economic Change. Cambridge: Bellknap Press.

Penrose, Edith T. (1959): The Theory of the Growth of the Firm. Oxford: Oxford University Press.

Peteraf, Margaret A. (1993) : The Cornerstones of Competitive Advantage: A Resource-Based View. Strategic Management Journal 14: 179-191.

Polanyi, Michael (1958): Personal Knowledge: Towards a Post-Critical Philosophy. Chicago: University of Chicago Press.

Porter, Michael. (1980): Competitive Strategy. New York: Free Press.

Prahalad, C.K. and Gary Hamel (1990): The Core Competence of the Corporation. Harvard Business Review 66: 79-91.

Rabin, Matthew (1993): Information and the Control of Productive Assets. Journal of Law, Economics, and Organization 9: $51-76$

Reed, R. and R.J. DeFilippi (1988): Causal Ambiguity, Barriers to Imitation, and Sustainable Competitive Advantage. Academy of Management Review 15: 88-102.

Reve, Torger (1990): The Firm as a Nexus of Internal and External Contracts. In Masahiko Aoki, Bo Gustaffson, and Oliver E. Williamson (eds.) (1990): The Firm as a Nexus of Treaties. London: Sage.

Richardson, George B. (1972): The Organisation of Industry. Economic Journal 82: 883-896.

Rumelt, Richard P. (1984): Towards a Strategic Theory of the Firm. In Lamb, R.B. (ed.) (1984): Competitive Strategic Management. Englewood Cliffs: Prentice-Hall.

Silver, Morris (1984): Enterprise and the Scope of the Firm. Aldershot: Martin Robertson.

Teece, David J. (1982): Towards an Economic Theory of the Multiproduct Firm. Journal of Economic Behavior and Organization 3: 39-63.

Teece, David J. (ed.) (1987a): The Competitive Challenge. Cambridge: Ballinger Publ. Comp.

Teece, David J. (1987b): Profiting from Technological Innovation: Implications for Integration, Collaboration, Licensing and Public Policy. In idem. (1987a).

Teece, David J. (1990): Contributions and Impediments of Economic Analysis to the Study of Strategic Management. In Fredrickson, J.M. (ed.) (1990): Perspectives on Strategic Management. Grand Rapids: Harper Busienss.

Teece, David J., Gary Pisano and Amy Shuen (1995): Firm Capabilities, Resources, and the Concept of Strategy. Forthcoming in Strategic Management Journal.

Walker, G. and D. Weber (1984): A Transaction Cost Approach to the Make or Buy Decision. Administrative Science Quarterly 29: 373-391.

Wernerfelt, Birger. (1984): A Resource-Based View of the Firm. Strategic Management Journal 5: 171-180. 
Williamson, Oliver E. (1985): The Economic Institutions of Capitalism. New York: The Free Press, New York, 1985.

Williamson, Oliver E. (1991a): Strategizing, Economizing, and Economic Organization. Strategic Management Journal 12: 75-94.

Williamson, Oliver E. (1991b): Comparative Economic Organization: The Analysis of Discrete Structural Alternatives. Administrative Science Quarterly 36: 269-296.

Winter, Sidney G. (1987): Knowledge and Competence as Strategic Assets. In David J. Teece (1987a).

Winter, Sidney G. (1988): On Coase, Competence and the Corporation. Journal of Law, Economics and Organization 4: 163-180. 


\section{$\mathbf{D}_{\text {anish }} \mathbf{R}_{\text {searrth }} \mathbf{U}_{\text {nit tor }} \mathbf{I}_{\text {nusurtial }} \mathbf{D}_{\text {samisis }}$}

The Research Programme

The DRUID-research programme is organised in 3 different research themes :

- The firm as a learning organisation

- Competence building and inter-firm dynamics

- The learning economy and the competitiveness of systems of innovation

In each of the three areas there is one strategic theoretical and one central empirical and policy oriented orientation.

\section{Theme A: The firm as a learning organisation}

The theoretical perspective confronts and combines the ressource-based view (Penrose, 1959) with recent approaches where the focus is on learning and the dynamic capabilities of the firm (Dosi, Teece and Winter, 1992). The aim of this theoretical work is to develop an analytical understanding of the firm as a learning organisation.

The empirical and policy issues relate to the nexus technology, productivity, organisational change and human ressources. More insight in the dynamic interplay between these factors at the level of the firm is crucial to understand international differences in performance at the macro level in terms of economic growth and employment.

\section{Theme B: Competence building and inter-firm dynamics}

The theoretical perspective relates to the dynamics of the inter-firm division of labour and the formation of network relationships between firms. An attempt will be made to develop evolutionary models with Schumpeterian innovations as the motor driving a Marshallian evolution of the division of labour.

The empirical and policy issues relate the formation of knowledge-intensive regional and sectoral networks of firms to competitiveness and structural change. Data on the structure of production will be combined with indicators of knowledge and learning. IO-matrixes which include flows of knowledge and new technologies will be developed and supplemented by data from case-studies and questionnaires. 


\section{Theme C: The learning economy and the competitiveness of systems of innovation.}

The third theme aims at a stronger conceptual and theoretical base for new concepts such as 'systems of innovation' and 'the learning economy' and to link these concepts to the ecological dimension. The focus is on the interaction between institutional and technical change in a specified geographical space. An attempt will be made to synthesise theories of economic development emphasising the role of science based-sectors with those emphasising learning-byproducing and the growing knowledge-intensity of all economic activities.

The main empirical and policy issues are related to changes in the local dimensions of innovation and learning. What remains of the relative autonomy of national systems of innovation? Is there a tendency towards convergence or divergence in the specialisation in trade, production, innovation and in the knowledge base itself when we compare regions and nations?

\section{The Ph.D.-programme}

There are at present more than 10 Ph.D.-students working in close connection to the DRUID research programme. DRUID organises regularly specific Ph.D-activities such as workshops, seminars and courses, often in a co-operation with other Danish or international institutes. Also important is the role of DRUID as an environment which stimulates the Ph.D.-students to become creative and effective. This involves several elements:

- access to the international network in the form of visiting fellows and visits at the sister institutions

- participation in research projects

- access to supervision of theses

- access to databases

Each year DRUID welcomes a limited number of foreign Ph.D.-students who wants to work on subjects and project close to the core of the DRUID-research programme.

\section{External projects}

DRUID-members are involved in projects with external support. One major project which covers several of the elements of the research programme is DISKO; a comparative analysis of the Danish Innovation System; and there are several projects involving international cooperation within EU's 4th Framework Programme. DRUID is open to host other projects as far as they fall within its research profile. Special attention is given to the communication of research results from such projects to a wide set of social actors and policy makers. 


\section{DRUID Working Papers}

96-1 Lundvall, Bengt-Åke: The Social Dimension of the Learning Economy. (ISBN 87-7873-000-7)

96-2 Foss, Nicolai J.: Firms, Incomplete Contracts and Organizational Learning. (ISBN 87-7873-001-5)

96-3 Dalum, Bent and Villumsen, Gert:Are OECD Export Specialisation Patterns 'Sticky?' Relations to the Convergence-Divergence Debate. (ISBN 87-7873-002-3)

96-4 Foss, Nicolai J: Austrian and Post-Marshallian Economics: The Bridging Work of George Richardson. (ISBN 87-7873-003-1)

96-5 Andersen, Esben S., Jensen, Anne K., Madsen, Lars and Jørgensen, Martin: The Nelson and Winter Models Revisited: Prototypes for Computer-Based Reconstruction of Schumpeterian Competition. (ISBN 87-7873-005-8)

96-6 Maskell, Peter: Learning in the village economy of Denmark. The role of institutions and policy in sustaining competitiveness. (ISBN 87-7873-006-6)

96-7 Foss, Nicolai J. \& Christensen, Jens Frøslev: A Process Approach to Corporate Coherence. (ISBN 87-7873-007-4)

96-8 Foss, Nicolai J.: Capabilities and the Theory of the Firm. (ISBN 87-7873-008-2)

\section{Information for subscribers.}

Subscription price for 1996 is 600 DKR (about 20 papers). The rate for single issues is 40 DKR. It is possible to make a commitment to an exchange of papers from related depart ments or research teams. All correspondence concerning the DRUID Working Papers should be send to:

Mette Madsen

Fibigerstræde 4, DK-9220 Aalborg OE

Tel. 45981542 11-2945

Fax. 4598156013

E-mail: mm@business.auc.dk 